\title{
Una expansión desigual. Los cambios en el consumo argentino, desde principios del siglo XX hasta la década de 1940
}

Fernando Rocchi

Universidad Torcuato Di Tella, Argentina. Correo electrónico: frocchi@utdt.edu

Artículo recibido: 03 de junio de 2019. Aprobación final: 12 de diciembre de 2019.

\section{Resumen $^{1}$}

Este artículo analiza la evolución del consumo en Argentina desde la primera década del siglo XX hasta 1940, con un acento especial en las transformaciones ocurridas en los tres periodos que recorrieron ese espacio de tiempo: la llamada Belle Époque que se desplegó entre 1903 y 1913, los catorce años de administración del Partido Radical entre 1916 y 1930 y, finalmente, los diez años que siguieron a la crisis económica iniciada en 1929. El objetivo es mostrar los cambios y las continuidades en relación con las cantidades y las calidades de los bienes demandados por la población. Por la influencia que ejercen sobre el consumo el nivel de ingresos (directamente relacionado con el salario real) y los grados de nutrición y salud, en el artículo no solo se muestra la evolución cuantitativa y cualitativa en el consumo de bienes, sino que también se analizan las desigualdades sociales y regionales que tuvieron directa relación con la distribución del gasto de las familias. Con ese fin, se analizan distintas fuentes y publicaciones, muchas de las cuales realizan estimaciones, junto con información cualitativa. 


\title{
An Unequal Expansion. Changes in Argentine Consumption Patterns, from the Early 20th Century to the 1940s
}

\begin{abstract}
This article analyzes the evolution of consumption in Argentina from the first decade of the twentieth century to 1940 , with a special emphasis on the transformations that occurred in the three periods that covered that space of time: the so-called Belle Époque that unfolded between 1903 and 1913, the fourteen years of administration of the Radical Party between 1916 and 1930 and, finally, the ten years that followed the economic crisis that began in 1929. The objective is to show the changes and continuities concerning the quantities and qualities of the goods demanded by the population. Due to the influence exerted on consumption by the level of income (directly related to real wages) and the levels of nutrition and health, the article not only shows the quantitative and qualitative evolution in the consumption of goods, but also analyses the social and regional inequalities that were directly related to the distribution of family expenditure. To this end, different sources and publications are analyzed, many of which make estimates, along with qualitative information.
\end{abstract}

Keywords: Consumption, Social History, Argentina in the Twentieth Century, Income Distribution, Regional Divergence.

\section{Introducción}

En 192l, el economista Alejandro Bunge -obsesionado por potenciar el ahorro nacional que eventualmente se convertiría en inversiones- creía que la sociedad de consumo había llegado demasiado lejos en la Argentina y entrado en la cultura del derroche:

\footnotetext{
Los obreros van a trabajar con botines de charol, con capellada gris. La gente acomodada renueva cada par de años parte de su mobiliario; tapiza de nuevo sus aposentos; gasta y despilfarra lo que tiene y lo que no tiene; descuenta el porvenir.
}

Una anécdota le revelaba a Bunge lo acertado de su argumento. Una señora de clase alta, después de visitar Francia y Alemania y admirarse por la prolijidad con que se realizaban compras para no excederse, le explicó a su ama de llaves los avances de la economía doméstica europea. Para su sorpresa, esta le contestó, consternada: “¿Ha visto, señora, no? ¡Lo que puede la miseria!” (Bunge, 1928, tomo I: 74-77).

Los estudios de consumo han proliferado en los últimos años en áreas como las condiciones de la vida material (Moreyra, 2000-2001), la alimentación (Remedi, 2006 y 2017, Ledesma, 2015 y 2017), los estudios de género (Milanesio, 2006, Tossounian, 2016, Pérez, 2017), la relación con el hogar (Caldo, 2009, Pérez, 2012), la elaboración de productos (Moyano, 2012 y 2017), el ocio (Pastoriza, 2002), la 
comercialización (Lluch, 2015), la formación de mercados (Martirén y Moyano, 2019) y la publicidad (Salvatore, 2005, Rocchi, 2016b y 2017). Tal ha sido el crecimiento en estas investigaciones que han dado lugar a estados de la cuestión sobre el tema (Pérez, 2015 y 2017, Rocchi, 2016a).

Este artículo indaga en la esfera de consumo material -que es un aspecto acotado de la demanda total (Trentmann, 2017)- con especial énfasis en los bienes que componían la canasta básica de su tiempo, donde ocupaban un lugar crucial los alimentos y la vestimenta, parte producidos localmente -sobre todo los primeros- y parte importados. El consumo depende directamente de variables como el nivel de ingreso y ejerce fuerte impacto en la nutrición infantil (que se muestra en las estaturas alcanzadas) y el estado de salud de los habitantes (Deaton, 2015). Por esta razón, en este análisis se pone especial énfasis en las desigualdades sociales y regionales de Argentina, en particular en los salarios reales, en los hábitos de alimentación y en la difusión de las enfermedades.

En primer lugar, el artículo estudia las características del consumo de bienes materiales en el periodo de la llamada Belle Époque de la primera década del siglo $\mathrm{XX}$, un momento de alto crecimiento del producto, pero con más acumulación de riqueza que distribución del ingreso. En segundo lugar, indaga en la década de 1920 y la evolución en las cantidades y las calidades del consumo en años en que, con menos crecimiento económico que a principios de siglo, se produjo una redistribución significativa del ingreso. Finalmente, analiza las transformaciones que se produjeron con la crisis de 1930, que llevó a una caída de un $20 \%$ en el ingreso, y cómo esas transformaciones impactaron en ese descenso, así como, durante la recuperación económica que comenzó a partir de 1933, lo hicieron sobre la canasta de bienes que definían la parte más importante de la demanda de la población.

Las fuentes analizadas provienen de distintas publicaciones de la época, muchas de las cuales realizan estimaciones, algunas más creíbles que otras, lo que ha llevado a contrastar datos de diferentes orígenes con información cualitativa. El Departamento Nacional de Trabajo (DNT), fundado en 1907, realizó una serie de estudios detallados sobre los salarios y los consumos de los obreros, aunque su foco estuvo en la Capital Federal, apareciendo de manera aleatoria y desigual los que corresponden al resto del país. Por otra parte, los realizados en la Revista de Economía Argentina por los discípulos de Bunge como Emilio Llorens, que sí alcanzan una visión más amplia, también ofrecen problemas sobre la forma de recolección de datos que obligan a contrastarlos con otras fuentes. En este contexto, el esfuerzo de un grupo importante de investigadores, la mayoría del interior de Argentina, por realizar estimaciones de ingresos, salarios y consumos es un recurso invalorable para obtener un panorama más completo del conjunto nacional, cuyos estudios son utilizados en este artículo. 


\section{La Argentina de principios del siglo XX: la macroeconomía de un país rico en medio de una sociedad desigual}

Durante el momento "dorado" de 1903-1913 la tendencia general fue la del estancamiento del salario real, aunque sí era más alto que en Italia o en España, de donde llegaba el grueso de la inmigración. Según las estimaciones realizadas para obreros de la ciudad de Buenos Aires, los salarios reales habían comenzado a crecer en 1896 (con la recuperación de la crisis de 1890) y alcanzaron un máximo en 1899; bajaron hasta 1903-1904 y, a partir de entonces y con una evolución más confusa, siguieron en declinación hasta 1907, hasta que subieron entre 1910 y 1912 (Cortés Conde, 1978: 236-237). Hubo similitudes y diferencias con el interior argentino. En el caso de la provincia de Córdoba, se produjo un considerable aumento en el precio de los alimentos entre 1900 y 1913, que no fue acompañado por los montos de los salarios nominales en los sectores de menor calificación (Remedi, 2004:309-310). Los salarios reales también tuvieron una fuerte caída en Mendoza, sobre todo en el caso de los peones de las bodegas, aunque fue menor en el sector público (Bragoni y Olguín, 2016: 166-167). En la provincia de Tucumán, por el contrario, los salarios reales aumentaron alrededor del 20\% entre 1903 y 1913 (Campi, 2004: 118-120, Sánchez Wilde, 1993). A pesar de los límites impuestos por un salario real generalmente estancado, la incorporación de más de un millón y medio de inmigrantes durante estos años amplió el mercado de consumo de manera consistente.

En el conjunto del país se produjo un estancamiento en la nutrición neta entre 1900 y 1913, como muestra el análisis de la altura de los soldados de veinte años reclutados para el servicio militar que habían nacido en esos años: la estatura promedio apenas subió de 1,681 a 1,682 metros (Salvatore, 2004a: 239). Este dato, sin embargo, debe matizarse: la migración que llegó a la Argentina a partir de 1900 (principalmente del sur de Italia y Galicia) tenía una estatura menor en sus lugares de origen comparada con la que recibió el país entre 1850 y 1900, mayormente proveniente del norte de Italia y de la región vasca española y francesa.

La dieta promedio básica de la Argentina estaba dada por siete bienes: carne, pan (muchas veces consumido como galleta), azúcar, papas, yerba mate, vino y, en ciertas zonas, el maíz. ${ }^{2}$ Si bien se habían realizado estimaciones sobre salarios reales y condiciones de vida de los obreros hasta la creación del DNT como las del enviado estadounidense William Buchanan en 1896, Adrián Patroni en 1897, Juan Alsina en 1905 y las que surgieron del informe Bialet-Massé, esta institución estatal intentará compilar información de manera más sistemática y detallada. Con el objetivo de enfrentar la cuestión social de manera más "científica" en momentos en que la estadística se afianzaba como disciplina (Otero, 2007; González Bollo, 2013), el Departamento comenzó con la búsqueda y construcción de datos que posibilitaran un diagnóstico adecuado de la situación de los trabajadores. Un grupo de técnicos y profesionales se convirtió en una legión de burócratas

2 República Argentina, Departamento Nacional de Trabajo (en adelante DNT), Boletín del Departamento Nacional de Trabajo, núm 36, enero de 1918, pp. 15-16. 
especializados en temas laborales, tomando como ejemplo las experiencias que se estaban desarrollando en Australia, Nueva Zelanda, Estados Unidos y España (Lobato, 2017: 149).

La carne y el pan eran alimentos básicos de los adultos, aunque la leche ocupaba un lugar especial en la de los niños, mientras que en los sectores más pobres como ocurría en Córdoba- la yerba mate ocupaba un rol esencial en la canasta de consumo, representando un 25\% del total entre los jornaleros y un 23\% entre las costureras, lo que también implicaba una mayor ingesta de azúcar pues en la Argentina de entonces el mate se tomaba dulce como fuente de energía (Remedi, 2004: 447). El DNT calculaba en 1917 que el 55\% del gasto mensual de una familia obrera de la capital argentina se dedicaba a alimentos, un 17\% a alquiler, un $16 \%$ a la ropa y el resto a carbón y gastos eventuales, como los de farmacia, transporte y publicaciones periódicas. De los egresos en comida 36\% correspondían a la carne, $24 \%$ a las papas, algo más de un $6 \%$ al azúcar, un $2 \%$ a la yerba, a lo que habría que añadir un porcentaje importante de pan. El gasto en ropa era significativo, especialmente entre los hombres que consumían más prendas que las mujeres, un dato significativo, y los niños. ${ }^{3}$

En la literatura académica, este tema ha cobrado una gran importancia desde los estudios pioneros de Leandro Gutiérrez y Roberto Cortés Conde. Gutiérrez analizó la vivienda, así como los precios y las adulteraciones en los alimentos, especialmente a fines del siglo XIX (Gutiérrez, 1981). Cortés Conde cuantificó los porcentajes que componían el consumo de las familias obreras de Buenos Aires entre 1897 y 1907 y concluyó que los gastos familiares se distribuían de la siguiente manera: $50 \%$ de alimentos, $20 \%$ de vivienda, $15 \%$ de vestimenta y $15 \%$ de varios (Cortés Conde, 1978, 286). Una reconstrucción del consumo en base a apreciaciones de Alfredo Palacios de 1892, incluye ciertos bienes y sus ponderaciones: trigo y/o pan (27\%), maíz (7\%), carne (28\%), vino (5\%), azúcar (3\%), alquiler (20\%) y ropa (10\%) (Cuesta, 2012).

En el año 1913 la Argentina tenía un índice de Gini de 0,491, un coeficiente elevado, propio de una economía cuya desigualdad parece haber sido fruto de una expansión económica demasiado acelerada. Entre los trabajadores, los del sector público eran los mejor ubicados (con un índice de 0,308), mientras que los del agropecuario (probablemente por el peso de los chacareros) no era malo $(0,377)$ y le seguían la industria y la construcción con un 0,421. El grupo que mostraba la mayor desigualdad era el comercial con un índice de 0,506; las condiciones de trabajo de los dependientes deben haber sido de las peores de todo el país. Una característica interesante de la economía mundial es que algunos de los países más pobres (como ocurre hoy en buena parte del África) tienden a ser más igualitarios que otros más ricos: la pobreza parece igualar las desgracias pues no hay un sector significativo que pueda concentrar riqueza simplemente porque es escasa. En 1913, las provincias más pobres eran las menos desiguales de la Argentina: el coeficiente de Gini de las del noroeste iba de 0,285 a 0,342. Los más 
altos estaban en la Capital Federal con 0,567, un número similar al de La Pampa, aunque menor que en San Luis, Santa Cruz, Córdoba, Santa Fe, Formosa, Entre Ríos, Chubut y Tucumán, cuyos índices iban del 0,495 a 0,429 (Salas Arón, 2019).

Estos datos reflejan lo que ya era un patrón histórico:que el país crecía de manera notoriamente desigual a nivel regional, como quedaba demostrado, para 1875, en la diferencial de salarios (Djenderedjian, en prensa). Las diferencias regionales fueron una característica del siglo XIX (Gelman, 2011) y han sido una constante desde entonces (Santilli, 2019). En el periodo 1913-1915, la esperanza de vida al nacer en la provincia de Buenos Aires era de 51,37 años, en el Centro Litoral de 48,75, en Cuyo de 41,45 y en el Noroeste de 37,94. La mortalidad infantil también era mucho más alta en el interior: 140,38, 174,02, 248,21 y 288,23 por mil, respectivamente (Somoza, 1973: 822-826). Las diferencias eran muy significativas: en 1897 la muerte de niños representaba el 11\% de todos los decesos en Buenos Aires mientras en Tucumán implicaban el 24\%. La comparación de la esperanza de vida en las ciudades de Córdoba y Buenos Aires también seguía esta tendencia: mientras que era algo superior en la primera en 1869, para 1895 la cordobesa era de 33,88 años mientras que la porteña era de 40,88; en 1914 la distancia se había ampliado y era de 34,68 frente a 48,63 años (Celton, 1998: 38).

Asimismo, la diferencia en los resultados de las políticas sanitarias entre Buenos Aires y el Litoral frente al resto del país era palmaria. Mientras ciudades como Buenos Aires dejaban de lado las pestes con la construcción de un sistema de aguas corrientes a partir de 1887, el panorama de epidemias de cólera en 1868 y 1886, de peste bubónica en 1899 y 1900 y de viruela en 1901 y 1902 en provincias como Salta pudo controlarse limitadamente. En el norte, además, siguieron otros graves problemas, como el paludismo y el mal de Chagas, además de la tuberculosis, que afectaba a todo el país, pero más marcadamente a dicha región (Sierra e Iglesias, 2005). Los efectos del paludismo eran devastadores: en el periodo 1912-1915, 262.433 personas habían sido diagnosticadas con esa enfermedad en Tucumán, 147.296 en Salta, 55.867 en Jujuy, 43.647 en Catamarca y 12.118 en La Rioja, conformando un total de 521.461 afectados (Carter, 2012: 41-42, 62).

El país que finalmente se formó evolucionó de una manera dual: mientras las provincias más pobres tenían una especial incidencia en la política a través de la elección del presidente en el Colegio Electoral y el Senado, las más ricas no dejaron de crecer económicamente y aceptaban políticas de convergencia de ingresos que no podían rechazar por el juego de poder armado por la Constitución de 1853. Los intentos de las provincias del interior por aplicar esa política tuvieron tantos éxitos como limitaciones. Después del fracaso de la experiencia de igualación de ingresos a nivel nacional en el gobierno de Miguel Juárez Celman, con su generosa emisión monetaria provincial y un ambicioso programa de construcción de ferrocarriles -que produjo mejoras en la situación fiscal de las provincias pobres en la segunda mitad de la década de 1880- el proteccionismo al azúcar y al vino se volvió la herramienta más importante de convergencia, aunque limitada a las provincias en las cuales se producían estos bienes (Gerchunoff, Rocchi y Rossi, 2008). El resto quedó librada a la voluntad y arbitrariedad del Estado central por 
realizar transferencias. En el periodo 1870-1876 ya comenzó a vislumbrarse la tendencia, que se profundizó en las décadas siguientes: a mayor pobreza, mayor cantidad de pesos per cápita de ayuda nacional (Llach, 2007).

Sin embargo, la ayuda a través de subvenciones del Estado a las provincias encontró en la crisis de 1890 un límite imposible de remontar (que explica que buena parte del conjunto de distritos pobres tuviera una caída mayor a la nacional en el producto en la década que siguió a la debacle). Mientras que en 1890 las provincias cubrían en 40\% del gasto consolidado, en 1914 el porcentaje era menor al 25\%. Recién se produjo una mejora en el período 1914-1917: mientras el presupuesto nacional per cápita cayó un 20\%, la baja en el de las provincias fue de un 10\% (Salas Arón, 2019b). La situación fiscal de estos distritos acompañaba, en buena medida, las distorsiones del producto geográfico. El promedio de la recaudación de todas las provincias era, en 1913, de 15 \$ moneda nacional per cápita. Seis de estas lo superaban: las del Litoral, Mendoza y Tucumán, mientras que nueve estaban por debajo: Córdoba, San Luis, San Juan, Corrientes, y el resto del norte del país. Los dos distritos que más recaudaban triplicaban esos ingresos respecto de los tres que recolectaban menos impuestos (Sánchez Katz, 2016: 61-62, Coria, 2004).

En la década de 1880 el producto per cápita del noroeste era de un 50\% a un 60\% del que tenía la región pampeana: exceptuando Tucumán, en el resto de las provincias de esa región representaba solo del 30\% al 40\% del conjunto del Litoral (Aráoz y Nicolini, 2015). En 1914 el ingreso per cápita promedio de la Argentina era de 530 \$ corrientes. Solo tres distritos lo superaban: la provincia de Buenos Aires, la Capital Federal y Santa Fe con números que iban de $\$ 632$ a \$592. El resto del concierto provincial tenía una cifra más baja que la nacional, aunque mostraba algunos casos excepcionalmente altos, fruto de alguna producción regional exitosa: Córdoba (por la zona cerealera del centro sureste), San Luis (con un producto excepcionalmente alto por el boom agrícola de su zona oriental), Jujuy (por los ingenios) y Mendoza (por el vino). La Rioja llegaba apenas a \$389, y de ahí seguían -en línea descendente- Tucumán, San Juan, Salta y Corrientes. Las que peores resultados arrojaban eran Catamarca y Santiago del Estero, con un producto per cápita de \$240 y \$228, respectivamente. Algunos territorios nacionales (en parte por su escasa población) -Santa Cruz, Tierra del Fuego y La Pampa- superaban el promedio nacional, mientras que en otros era más bajo que el del país: Chaco, Chubut, Formosa, Misiones, Neuquén, Río Negro y Los Andes (Aráoz y Nicolini, 2015: 13-19).

No resulta extraño que en provincias pobres y con problemas de salud y nutrición, el consumo fuera más bajo que en el promedio del país. El primer objetivo de las fábricas de la ciudad de Buenos Aires para expandir sus ventas fue la campaña de esta provincia y, en segundo lugar, el mercado que constituían "las colonias”, es decir la zona cerealera de Santa Fe y Córdoba, que tenía un consumo muy similar al de la capital argentina. La demanda del Noroeste se diferenciaba en calidad de la litoraleña, con productos de menor precio. Para una empresa de chocolates porteña no tenía sentido vender sus productos en una zona donde se elaboraban los artículos a mano, de calidad inferior "parecido al que traen los 
bolivianos a las provincias del Norte, bueno sólo para indios y que sería rechazado con horror por el estómago delicado de una elegante porteña”, como señalaban dos observadores en 1888 (Malaurie y Gazzano, 1888: 143). La Cervecería Río Segundo, de Córdoba, alcanzó un gran éxito adoptando una estrategia de especialización al concentrarse en la cerveza negra, más barata que los otros tipos, que encontraba en su provincia y el norte su principal mercado: en 1905, la mitad de su producción se consumía en Tucumán, Salta y Jujuy. ${ }^{4}$ Además, las divergencias alcanzaban al empaquetamiento: mientras que en el Litoral los comerciantes compraban paquetes de 22 kilos de galletitas, en el Noroeste solo aceptaban los de 17 y 18 kilos, lo que creaba problemas de comercialización (Rocchi, 2006: 125151). El norte mostraba formas-en cantidad y calidad—de consumo diferentes del Litoral, aun en productos con poca elaboración industrial como las harinas (Martirén y Moyano, 2019).

\section{La década de 1920: Una prosperidad determinada por la suerte, la política y el miedo}

La economía argentina comenzó a recuperarse en 1919 y creció casi sin pausa durante los años veinte: en 1929, el ingreso per cápita era un 32\% más alto que diez años atrás (Ferreres, 2010: 112). En la década de 1920, la suerte, la política y el miedo se conjugaron para mejorar el nivel de vida de los trabajadores. El factor suerte se relacionó con el comercio internacional. La revolución bolchevique, que había quitado del circuito a Rusia -uno de los principales competidores de Argentina en el mercado mundial de granos y lino-, se unió al colapso de economías exportadoras de Europa central y oriental por los problemas de la guerra y al aumento de la demanda del mercado interno de los Estados Unidos, que produjo una restricción a sus saldos exportables; si en 1909-1913, la participación de la Argentina en las exportaciones mundiales de cereales, lino y carne vacuna era del 23,5\%, en 1924-1928 alcanzó el 32,0\% y en 1929-1933 el 36,75\% (Gerchunoff, 2016: 46). El contexto económico internacional favorable llevó a un aumento en las exportaciones, ayudado por las mejoras en la productividad agrícola por la mecanización (entre 1921 y 1929 crecieron en valor un 87\%), que generó una entrada de divisas y alentó una mayor prosperidad. También las importaciones jugaron un rol importante en este sentido (en esos años crecieron más de un 50\%), lo que llevó a un incremento en los ingresos fiscales (basados en los impuestos de las aduanas), y permitió implantar los inicios de un Estado de Bienestar.

El componente político se produjo cuando la Unión Cívica Radical adoptó una postura obrerista y colocó a la cuestión social en el centro de la escena, algo que, en su visión, los conservadores no habían podido incorporar por falta de voluntad (Horowitz, 2015). El hecho transformador fue la Semana Trágica. El 16 de mayo de 1919, poco después de las huelgas y la represión, Hipólito Yrigoyen inauguraba

4 Unión Industrial Argentina (UIA, en adelante), Boletín de la Unión Industrial Argentina, 15 de septiembre, 1905, pp. 11-12. 
la puesta en marcha de un programa social. El presidente incluyó en su discurso al Congreso una sección llamada Legislación Social, aludiendo a la conciliación, al arbitraje y a la justicia social. Los salarios reales industriales privados en la ciudad de Buenos Aires se duplicaron entre 1918 y 1923, según el relevamiento del DNT, en parte por las medidas tomadas por la administración radical para luchar contra la "carestía de la vida", como la importación de un bien de consumo popular como el azúcar y el congelamiento de los alquileres urbanos en 1921. En provincias gobernadas por los radicales se producían situaciones similares. ${ }^{5}$

El elemento miedo se relaciona con la actitud de cooperación de los empresarios con sus trabajadores. Después del año 1919, marcado por una represión que hizo uso de fuerzas parapoliciales, las empresas se embarcaron en una política de mejora en las relaciones entre capital y trabajo dado que una enemistad sistemática con sus obreros ponía en peligro su principal objetivo, que era luchar contra la competencia de otras firmas. Un recorrido por las actas de las asambleas anuales de las sociedades anónimas industriales en la década de 1920 muestra las explicaciones de los directores a los accionistas por no haber obtenido ganancias mayores debido a los aumentos en los salarios y la reducción en la jornada laboral: el fantasma de la revolución bolchevique hizo que el miedo fuera lo suficientemente fuerte como para hacer concesiones. Ya en 1920 la fábrica de bolsas Salinas, la de bebidas Bilz, la cervecería Palermo, las cristalerías Rigolleau y la de bizcochos Canale comenzaron a aumentar los sueldos, otorgar premios y destinar dinero a fondos de socorro a su personal obrero. El ejemplo sería seguido en toda la década, incluyendo empresas, como la Compañía General de Fósforos, que hasta avanzaban en las jubilaciones. ${ }^{6}$ Esta estrategia encontró un aliado casi perfecto en la nueva tendencia del gremialismo argentino: el sindicalismo. La Unión Sindical Argentina, fundada en 1922, utilizaba como estrategia los arreglos entre el capital y el trabajo por rama o por fábrica antes que la huelga general.

La publicación sindicalista Bandera Proletaria mostraba su desprecio por la clase media que podía llegar a ser más poderosa que la europea por la movilidad social pues "aquí las fluctuaciones económicas son más rápidas. Los componentes de ella difícilmente bajan a las clases pobres, muy por el contrario se elevan a las clases ricas y adineradas" mientras que "a medida que suben los jornales obreros aumentan las entradas de esta clase media. Sin contar que ella también explota al trabajador". Sin embargo, el mismo diario consideraba como el ideal del consumo obrero a bienes típicos de la demanda de la clase a la que condenaba; ello resulta evidente a través del abanico de productos ofrecidos como premio en las rifas por presos y giras de propaganda: juegos de muebles, máquinas de coser, juegos de mesa y de cubiertos, relojes para hombres y mujeres, así como sombreros masculinos y carteras femeninas. ${ }^{7}$

5 DNT, Crónica mensual, diciembre de 1923, pp. 1185-1186.

6 (Noviembre de 1920), Monitor de Sociedades Anónimas, pp. 144-145 y 150; (1923), tomo XXXVI, p. 27, 51 y pp. 106-107; (1929), Tomo XLVIII, p. 21.

7 (26 de septiembre de 1925), Bandera Proletaria, p. 4; (28 de abril de 1928), p. 3 y (9 de abril de 1929), p. 3. 
El aumento de los salarios reales en los años veinte ya había sido advertido por Alejandro Bunge, que calculaba que había sido de un 50\% entre 1919 y 1927 y resultaba, según el economista, uno de los motivos para explicar la falta de competitividad de la producción manufacturera argentina (Bunge, 1928, tomo II: 222-223). Estimaciones más modernas llevan el aumento en los salarios industriales de la ciudad de Buenos Aires, donde se ubicaba por entonces el grueso de las fábricas argentinas, a más de un 60\% entre 1920 y 1929 (Gerchunoff y Aguirre, 2006; Gerchunoff, 2016; Cuesta, 2014), aunque otras aseguran que hubo una subestimación de la suba de precios, por lo que el aumento del salario real habría sido menor, aunque igualmente significativo (Lanata Briones, 2016: 90-142).

Después del gran salto en los salarios reales de 1919 a 1923, que implicó en parte una recuperación de los valores perdidos durante la guerra, a partir de 1924 los aumentos en las retribuciones nominales fueron más modestos, aunque la deflación producida por la apreciación del peso hizo que crecieran casi 20\% entre 1923 y 1928. En la provincia de Tucumán el salario real del obrero industrial aumentó un 108\% entre 1918 y 1927, mientras que el del trabajador azucarero, que ganaba menos, lo hizo un $174 \%$, una evolución en parte relacionada con la huelga del sector en 1923 (más la ley de salario mínimo y jornada de ocho horas, resultado de la posición favorable a los trabajadores del radicalismo provincial) (Correa Deza, 2007).

No resulta extraño el clima social que se vivió en los años veinte. Disminuyó la jornada laboral, que llegó a ser de ocho horas en la ciudad de Buenos Aires, mientras se regulaba aún más el trabajo de mujeres y niños y se establecía el domingo como día no laborable. Después de los graves conflictos sociales de 1917 y, sobre todo, de 1919, en la década de 1920 la lucha social disminuyó en cantidad y en intensidad en la región pampeana y en las grandes ciudades de Argentina (aunque en las zonas más periféricas como la Patagonia, el Norte azucarero y yerbatero, y la zona de producción de tanino en la región del Chaco se producían huelgas intensas y represiones sangrientas). El mayor conflicto, en términos de cantidad de obreros en huelga en la región pampeana, se produjo en 1927 en solidaridad por la ejecución de Nicola Sacco y Bartolomeo Vanzetti en los Estados Unidos (Horowitz. 2015: 78).

En la década de 1920 debieron producirse mejoras salariales en el mundo rural pampeano. Como en las remuneraciones urbanas, en las rurales se concretó un aumento significativo en términos nominales (en años de deflación), lo que afectó los costos de producción del agro, sobre todo en el primer lustro de los años veinte. Resulta muy probable que esta coyuntura alcista haya acelerado un nuevo proceso de cambio técnico en la agricultura pampeana, que se reflejaría en saldos crecientes de importaciones de maquinarias ahorradoras de mano de obra de mayor porte (como cosechadoras) y en el incipiente proceso de tractorización (esto es, reemplazo de la tracción a sangre por motores a combustión) que tuvo lugar en las pampas en la década de 1920. Si bien el proceso de expansión cerealera que había explotado desde fines de la década de 1880 se había realizado sobre la base de incorporación de tecnología importada, desde 1920 Argentina se 
convirtió en uno de los más grandes importadores mundiales de implementos y maquinaria agrícola (Pineda, 2018). El negocio fue de tal magnitud que, en 1921, La Cantábrica -una de las empresas metalúrgicas más grandes del país- comenzó con la compra de este tipo de bienes desde Canadá, que se convertiría en uno de sus principales negocios: los valores de las máquinas importadas se triplicaron entre 1922 y 1925.8

En los años veinte, el consumo de carne vacuna a nivel nacional se incrementó notablemente. Había venido cayendo desde los 63,7 kilos per cápita de 1914 a los 46,4 de 1920 (el año de más bajo consumo de la historia del siglo XX), pero fue subiendo paulatinamente hasta una cifra en 1929 que va de los 74,4 a los 93,5 kilos, según la estimación considerada (Llorens, 1942; Ferreres, 2012). Una explicación bastante plausible sobre este incremento tan sustancial radica en la tradición histórica por la cual los individuos que están dejando la pobreza tienen una propensión declarada por la ingesta de carne, como les ocurría a los inmigrantes que llegaban al país, de la misma manera que aumentó la demanda de cortes vacunos y de cordero entre los obreros de la revolución industrial inglesa y la porcina y avícola con las transformaciones de la China contemporánea a partir de 1978.

El consumo de pan, medido en trigo molido, después de las caídas brutales de 1919 y 1920, aumentó de manera poco considerable: pasó de un promedio de 146,7 kilos per cápita en 1921 a 150,6 en 1929, si tomamos las estimaciones de la Revista de Economía Argentina (Llorens, 1942: 219), lo que parece indicar que se había satisfecho su demanda básica, en parte debido a los avances en la industria molinera local (Martirén y Rayes, 2016). El país se había convertido en un gran consumidor de pan per cápita, el segundo después de Chile en América Latina y el cuarto en el mundo (Llorens, 1942: 79). La demanda de mantequilla -que había pasado a ser llamada manteca- aumentó con una dieta argentina que la asociaba con el pan en el desayuno: su consumo per cápita creció de 0,68 a 0,84 kilos en los años veinte. De manera similar, el de quesos pasaba de 1,4 a 1,8 kilos anuales por habitante, un resultado directo de la demanda de los inmigrantes. Paralelamente disminuía el consumo de papas, un bien inferior (es decir, cuya demanda decrece con el aumento en el ingreso) que era asociado con la pobreza (el precio de un kilo de papas equivalía a la mitad de uno de pan y a un cuarto de uno de carne): en este producto alimenticio se mostró un caso notable de cambio de dieta pues los niveles históricos de más de 100 kilos por habitantes que se dieron hasta 1920 cayeron hasta menos de 68 kilos en la segunda mitad de la década. ${ }^{9}$

El consumo per cápita de azúcar también repuntó. Después de una caída entre 1916 y 1918, entre 1919 y 1921 se produjo un aumento en la demanda y en el periodo 1920-1924 alcanzó una cifra cercana a los 22 kilos per cápita, todavía menor a los 26,63 de 1914. Sin embargo, entre 1925 y 1929 llegó a los 30,75 kilos, los más altos hasta ese momento (Centro Azucarero Nacional, 1935:93-94).

8 La Cantábrica S.A., Actas del Directorio del 23 de septiembre de 1926.

9 (Junio de 1941), Revista de Economía Argentina, núm 288, pp. 158-160. 
Además, el aumento en el consumo de galletitas -un artículo considerado hasta entonces de lujo- llevó a un incremento en la demanda de azúcar. El ingenio San Martín de Tabacal, de la provincia de Salta, que se convertirá en uno de los más importantes del país en la década de 1920, estaba formado por una sociedad compuesta por la familia Patrón Costas con Pedro Mosoteguy y Pedro Bercetche (estos últimos los dueños de Bagley, la mayor fábrica de galletitas del país, que se convirtió en cliente preferencial de los azúcares de la nueva empresa salteña) (Sweeny y Dominguez Benavides, 1998: 95-113). Por otra parte, la calidad del azúcar elaborado en el país había mejorado con los procesos de refinamiento en los ingenios (que se había iniciado a fines del siglo XIX) y con la elaboración de azúcares blancos no refinados (Moyano, 2012 y 2017).

El consumo de yerba se incrementó de 7,7 a 8,4 kilos entre 1920 y 1929 y produjo el consecuente aumento en la demanda de azúcar, mientras el de café se mantuvo estable (pasó de 2,17 a 2,12 kilos) (Llorens, 1942: 75). Los esfuerzos británicos por imponer el té con sus campañas de "Drink more Tea" y la profusión de su publicidad para desplazar al mate fueron inútiles. Chile, el mayor demandante de té en América Latina, superaba en dos veces y media el índice per cápita de Argentina. Un informe consular británico confirmaba con tristeza que "el consumo de té está limitado a una parte muy pequeña de la población”. A pesar del refinamiento que supuestamente implicaba tomar el té a la británica, su consumo per cápita bajó de 0,21 a 0,16 kilos entre 1910-1919 y 1920-1929. ${ }^{10}$

Durante la década de 1920 volvió a incrementarse -como ocurría desde fines del siglo XIX- el consumo de cerveza, una bebida refrescante para los sofocantes veranos del centro y del norte de Argentina, que pasó de los 11,3 litros per cápita de los años 1910-1919 a los 18,3 en 1920-1929. Si bien estas cifras estaban lejos de los niveles alcanzados en el norte y centro de Europa (en donde superaban los cien litros) su incidencia relativa para un país poco bebedor resultaba importante. ${ }^{11}$ Durante el verano el consumo de cerveza igualaba al del vino, bebida cuyo consumó fue relativamente estable, aunque cayó, de 59,5 a 57,6 litros per cápita en la década de $1920 .^{12}$

Un consumo emergente fue el del aceite que fue reemplazando a la grasa -que empezó a ser asociada con la pobreza y lo primitivo- en la cocción de los alimentos. El aceite comestible - de oliva en su versión cara y maní y nabo en la barata- fue uno de los bienes que experimentó un aumento más significativo en la demanda per cápita: pasó de cuatro a superar seis litros por habitante entre 1910-1914 y los años veinte. Entre este producto todavía predominaba el producto importado: en 1930 los aceites nacionales alcanzaban a representar solo un $27 \%$ de la demanda nacional. ${ }^{13}$ Los inmigrantes generaban una demanda por productos que llegaban de España e Italia para satisfacer sus gustos étnicos:

10 United Kingdom, Department of Trade, Report for the year 1929, p. 52.

11 United Kingdom, Department of Trade, Report for the year 1925, p. 55.

12 (Junio de 1941), Revista de Economía Argentina, núm 288, pp. 158-160

13 (Junio de 1941), Revista de Economía Argentina, núm 288, p. 160. 
durante la década de 1920, la importación de aceite de oliva aumentó de 14 mil a 60 mil toneladas, la de aceitunas se duplicó, la de sardinas aumentó un $60 \%$ y la de pasta de tomate se triplicó. ${ }^{14}$

A niveles regionales se producían algunas diferencias respecto del promedio general del país. En el caso de Tucumán se afirmaba la presencia del maíz: las estimaciones muestran una canasta de bienes en la que ocupaba el 20\% del consumo, a lo que se sumaba un 30\% para la carne, un 30\% para la harina de trigo, y un 5\% para el azúcar, así como el mismo porcentaje para el arroz, la yerba y el vino (Correa Deza, 2008: 4). En Córdoba la dieta de la ciudad y de su región cerealera era similar a la del Litoral, aunque entre los sectores rurales de más antigua ocupación predominaba el maíz, especialmente en el noroeste de la provincia (Remedi, 2004: 105, 117, 448-451). El presupuesto mensual de una familia en Mendoza en 1927, en una dieta con una participación mucho menor de pan que en la región pampeana, estaba compuesto en un $45 \%$ por alimentos, subdivididos, a su vez, en carne -que representaba un 17\%-, un 6\% de azúcar, un 4\% de maíz, un 1\% de harina y un 4\% de yerba (Richard-Jorba, 2010).

La década del veinte marcó un efecto calidad en el consumo que parecía el mejor ejemplo de una sociedad pujante. Si en el descenso de bienes inferiores el caso paradigmático fueron las papas, en el de bienes superiores fue la vestimenta, que alcanzó cotas que mostraban un nivel de vida relativamente bueno dentro del contexto latinoamericano. En 1929, el consumo de tejidos de lana y algodón en Argentina llegaba a los 1.180 gramos por persona, mientras en Chile, que ocupaba el segundo lugar en Sudamérica, era de 420 gramos. En cuanto al calzado de cuero, Argentina consumía 1,31 pares per cápita por año y Chile 0,7 pares (Poblete Troncoso, 1946: 163-168).

Si bien no era novedoso, el objetivo que pusieron las empresas en vender a las mujeres alcanzó en esos años una profundidad inusitada, tanto en su rol de ama de casa como en la introducción de bienes nuevos. La traducción de "La mujer como cliente" por parte de la revista Industria de los publicitarios argentinos concluía que el ama de casa era la mejor aliada del comercio al por menor: la publicación aconsejaba el uso del "educational advertising” y sus largos textos pensados para ser leídos por una mujer (los publicitarios argentinos pensaban que dedicaban más tiempo a la lectura de diarios y revistas que los hombres). ${ }^{15}$

La mujer, además, cumplió otro papel en la publicidad. En los años veinte se produjo un incremento exponencial en la importación de los nuevos bienes industriales: automóviles, cámaras fotográficas, celuloide para películas. La compra de automóviles fue tal que llevó a que en 1928 su número llegara a los 259.120 autos, la gran mayoría circulando por la región pampeana. La ilustración de nuevos productos con imágenes de mujeres -como ocurría con

14 (Febrero de 1934), Revista de Economía Argentina, núm 188, p. 60. Esto le dio a Italia y España el tercer y cuarto puesto en las importaciones argentinas después de Gran Bretaña y los Estados Unidos. Ver (Fernández, 2004).

15 (Julio de 1920), Industria, p. 1; (Julio de 1922), Industria, p. 2 y (Diciembre de 1922), Industria, pp. 1-4. 
los automóviles o con las cámaras fotográficas de la empresa Kodak- contenía un mensaje claro para una sociedad machista: si una clientela femenina podía usar este novedoso aparato, nade le impediría al hombre hacerlo, llegando hasta a emplear a mujeres vendedoras que mostraban cuán sencillo era conducir un automóvil. ${ }^{16}$

La convergencia social que se produjo en la década de 1920 con el aumento en el nivel de ingresos de la clase obrera y el incremento en el número de la clase media tuvo un correlato relativo en la divergencia que se producía en la geografía argentina. La estatura promedio de todo el país, que apenas había subido un milímetro entre los nacidos entre 1900 y 1913,mostró un resultado diferente en los años veinte: las alturas aumentaron de 1,682 entre los nacidos en 1920 a 1,695 metros a los que lo hicieron en 1929. La divergencia regional continuó, con estaturas más elevadas en la zona pampeana que en el Interior, pero el aumento relativo fue más grande en esta última área: mientras entre 1921 y 1929 la altura media de los reclutas de la primera zona se incrementó en 1,9 centímetros, en la segunda llegó a los 2,4 centímetros (Salvatore, 2004a: 239-240). Algunas provincias, como Mendoza y Córdoba, mostraron signos de convergencia con el Litoral.Los índices de mortalidad entre la ciudad de Buenos Aires y la provincia de Córdoba, si bien siguieron siendo diferentes, tendieron a asimilarse: en 1920 era de 24 por mil en la ciudad de Córdoba, de 18 en la provincia y de 16 en la ciudad de Buenos Aires, mientras que en 1930 eran de algo más de 17, 14 y 12,5 en la capital argentina (Celton, 1992: 35). Sin embargo, no ocurrió lo mismo con otras provincias. Entre 1910 y 1925 la mortalidad infantil era de 88,61 por mil en la Capital Federal y de 97,47 en la provincia de Buenos; pero en San Juan, Salta y Jujuy superaba el número de 200 (Carter, 2012: 75).

Además de algunas diferencias regionales que parecían decrecer (aunque sea moderadamente) y probablemente por una idea de nacionalidad que obligaba a toda empresa argentina a llegar hasta las fronteras del país, la clientela del interior pasó a ser -en la década de 1920- más atractiva para las empresas de Buenos Aires y de otras ciudades del Litoral. La idea de construir un verdadero mercado nacional pasó a ser una obsesión en esos años. Además, legislaciones provinciales llevaron a una limitada apertura de fábricas fuera de Buenos Aires, como ocurrió con la Compañía General de Fósforos en Tucumán, Santa Fe, Córdoba y Corrientes. ${ }^{17}$ Mientras tanto, comenzó a desplegarse en la década de 1910 una red de viajantes -muchos representantes exclusivos de las firmas del Litoral- y corredores por todo el país que terminó de conformarse en la de 1920. Un diario de La Rioja explicaba, en 1918, el papel crucial del comisionado pues "OTORGA INMEDIATAMENTE créditos que de otra manera sería muy difícil de obtener". ${ }^{18}$ La empresa de transportes Expreso Villalonga, especializada en llevar mercaderías de las estaciones de tren a los domicilios, si bien declaraba que "En otras épocas las casas de comercio se veían a menudo

16 (Noviembre de 1924), Industria, pp. 1-2.

17 Compañía General de Fósforos, Acta del directorio del 15 de junio de 1925.

18 (15 de febrero de 1918), El Independiente, La Rioja, p. 3. 
en dificultades para servir a sus clientes del interior" desplegó una intensa actividad en esa zona en los años veinte al ocuparse del cobro de las ventas. ${ }^{19}$

En la formación del mercado nacional, el uso de la marca como distintivo de calidad y confianza resultó una estrategia fundamental: su número se duplicó en relación con la década previa, en lo que Andrea Lluch llama una "inflación marcaria", que no solo alcanzaba a productos de sofisticación industrial (Lluch, 2013). Inclusive en bienes agroindustriales relativamente simples de producir, como la harina y el azúcar, la marca resultó crucial para poder conquistar el mercado (Martirén y Moyano, 2016).

\section{La crisis de 1930 y los años posteriores: un efecto diferenciado}

Si bien localmente no se reprodujeron los problemas de desempleo tan agudos de los países más afectados por la crisis, como los Estados Unidos y Alemania, entre 1930 y 1932 el ingreso per cápita de Argentina se redujo en un 20\%. La recuperación económica comenzó a partir de 1933 y en 1937 ya se habían superado los niveles previos a la crisis. El año de mayor desempleo fue 1932, cuando había 333.997 personas inscriptas como desocupadas. En 1935 el número había caído a 89.656 y en 1936 a $44.471 .^{20}$ En medio del clima deflacionario posterior a la crisis, los precios de varios bienes de consumo masivo cayeron: entre 1929 y 1939 el del pan bajó un 9\%, mientras que la harina lo hizo un 15\%, las pastas un $30 \%$, la yerba se desplomó de $\$ 1,20$ a 0,70, las papas -cuyo precio, como dijimos anteriormente, era la mitad del pan y un cuarto de la carne- mantuvieron valores estables, la carne apenas subió un 1\%, el arroz un 4\% y el azúcar granulado un $7 \%$. La deflación permitió que el consumo no cayera todavía más.

En 1931 el consumo de azúcar bajó en 38.000 toneladas, volvió a aumentar un año más tarde en 9.000 toneladas, pero descendió nuevamente en 1933. En 1934 se produjo un importante repunte y alcanzó a los 28,47 kilos per cápita, una cifra no muy lejana de los más altos índices alcanzados en el quinquenio 1925-1929. La caída de 1932 era explicada por el Centro Azucarero Nacional como un descenso en el consumo "que como es sabido abarcó a todos los artículos sin excepción, incidió particularmente sobre aquellos productos menos indispensables, afectando principalmente al azúcar entre los comestibles", pues era una tendencia mundial que aquellos bienes que no fueran totalmente imprescindibles para la subsistencia, cayeran durante una crisis económica (Centro Azucarero Nacional, 1935: 93-94).

Desde la perspectiva de los estudios antropométricos, este período parece haber afectado positivamente el componente nutricional básico de la población. La altura de los varones argentinos nacidos entre 1930 y 1940 subió de 1,694 a 1,715

19 (7 de septiembre de 1922), La Nación, p. 4.

20 DNT, Boletín del Departamento Nacional de Trabajo, núm 220-221-222, Epoca VII, 1939, p. 5319. 
metros, lo que sugiere que no hubo caída en el consumo alimentario básico (el aumento en las calorías ingeridas subió de 2.949 a 3.342) (Salvatore, 2010: 158159). El cambio en el consumo resultó en una sustitución de calidades que no era determinante para influir en la nutrición: los consumidores no dejaron de demandar los bienes básicos, aunque lo hicieron con productos que hoy serían identificados como de segundas marcas.

La clase media no cambió sus patrones de consumo en cuanto a calidad y cantidad una vez que, a partir de 1934, comenzó a recuperarse la economía. No ocurrió lo mismo con los sectores populares que vieron menguar su participación en la sociedad de consumo (Hora, 2015). La década de 1930 se caracterizó por un relativo estancamiento -después de una caída inicial-de los ingresos, lo que nos ofrece la contracara del período previo y nos hace esperar transformaciones ligadas a esta nueva realidad. Entre 1929 y 1939, el salario real, de acuerdo con los datos de la Dirección de Estadística Social del DNT, en realidad había caído un 3\%, aunque había habido momentos de aumentos en 1932 y $1935 .{ }^{21} \mathrm{El}$ salario real industrial, que en 1930 era un 70\% del de los Estados Unidos, en 1934 había llegado a ser un 57\% y en 1938 a un 50\% de los percibidos en este país (Iñigo Carrera, 2007, 205). Las remuneraciones de los trabajadores de la industria de mayor expansión en la década de 1930 -la textil- se mantuvieron en niveles bajos, probablemente por la alta incidencia del empleo de mujeres jóvenes, por la disparidad de género en las sumas pagadas. Este costo de trabajo permitió que la Argentina alcanzara un alto nivel de exportaciones industriales con la Segunda Guerra Mundial, que en 1943 llegaron a ser del 19,44\% de las totales. Ello se debió a que se concentraban en las ramas mano de obra intensiva como la alimentación y la textilería, en las cuales los bajos salarios las volvían competitivas (Llach, 1984: 532). La sociedad se volvió más desigual y especialmente afectó a los más pobres. La concentración de riqueza en manos del 1\% que pagaba los impuestos directos más altos a partir de la instauración de la tributación a los réditos de 1932 era muy alta: el 1\% más rico de la Argentina recibía el 18,77\% del ingreso nacional en 1932 y llegaba al 20,40\% en 1936. Con una estabilidad en los niveles de consumo de la clase media, esto sugiere un empeoramiento en las condiciones de vida de los sectores populares (Alvaredo, 2007: 264).

Las diferencias entre el consumo promedio y el de una familia obrera de la ciudad de Buenos Aires en 1936 eran reveladoras de las diferencias de ingresos. Un estudio del DNT mostraba que los obreros de la capital argentina apenas consumían un $42 \%$ del promedio nacional de carne y un 55\% del de pan (Llorens, 1942: 101-104). A fines de la década de 1930 una familia obrera de la ciudad de Buenos Aires con tres hijos menores de 14 años consumía 35 kilos de pan, 24 de papas, 24 de carne, 2 de harina (a lo que hay que agregar casi 6 de pastas), 4,5 de aceites, 3,2 de azúcar y 2,5 de yerba. Todas estas cantidades eran inferiores al promedio general. ${ }^{22}$ 
Los efectos de la crisis se reflejaron en la cantidad y calidad de los productos que habían logrado gran visibilidad en los años 20. La caída en las importaciones llevó a un colapso en el consumo de los bienes nuevos como los automóviles. Pero en los que siguieron demandándose masivamente, cayó la calidad. Así, en la década de 1930 el pan de segunda resultó el más consumido, mientras que en la carne primaron los cortes más económicos, como el puchero, la falda y el garrón (Remedi, 2004: 132). Los bajos precios relativos del pan respecto de la carne, cuyos aumentos esporádicos volvían su consumo más volátil, aumentaron al comienzo de la crisis su participación en la demanda de alimentos. El consumo de carne vacuna era grande: casi la tercera parte de Estados Unidos, Canadá y el Reino Unido y Alemania, la mitad de Australia y un tercio menor que Francia. En general, la Argentina se mantuvo en altos niveles generales de consumo, como muestra el Cuadro 1.

Cuadro 1. Tabla de indicadores relativos de consumo 1934-1938. Estados Unidos base 100. Fuente: (Bennett, 1951: 646-648)

\begin{tabular}{cc}
\hline País & \\
\hline Estados Unidos & 100 \\
Canadá & 83,7 \\
Australia & 80,6 \\
Reino Unido & 76,6 \\
Alemania & 60,7 \\
Francia & 57,3 \\
Argentina & 50,4 \\
Checoeslovaquia & 45,2 \\
Japón & 38,0 \\
Cuba & 37,3 \\
Italia & 35,8 \\
Unión Sudafricana & 34,8 \\
España & 32,8 \\
Unión Soviética & 31,2 \\
Brasil & 29,3 \\
México & 26,6 \\
\hline
\end{tabular}

La crisis afectó más a los bienes con mayor elasticidad a la variación de precios, como el azúcar y las bebidas. Entre 1930 y 1933, el precio del azúcar pilé (de mayor calidad y precio) aumentó un 15\% y el de la granulada (cristal, en terrón o molida) un $22 \%$, en el contexto de una economía deflacionaria, lo que llevó a una caída en el consumo de azúcar de un 4\% entre 1930 y 1933. En 1936, sin embargo, justamente con mejores precios, el consumo ya había vuelto a los niveles anteriores a la crisis. ${ }^{23} \mathrm{El}$ mercado del azúcar evolucionó durante los peores momentos de la crisis en la preferencia por la baja calidad: los ingenios tucumanos redujeron la producción de azúcares refinados en beneficio de los granulados entre 1929 y 1931 y los jujeños y salteños extendieron esa tendencia hasta 1932. Sin embargo, los tucumanos recuperaron el porcentaje del producto de mayor calidad de 1929 en el año 1932 (un 45\%), mientras que ya en 1933 ese tipo de azúcar representaba el 56\%; los ingenios jujeños y tucumanos recién en 1933 lograron un porcentaje de pilé similar al de 1929 (Moyano, 2017). 
El consumo de yerba mate cayó un 16\% entre 1929 y 1932, con una recuperación más lenta: no fue hasta 1940 que se superaron los números de los años veinte (a pesar de haber crecido la producción nacional de yerba y disminuido la importación). Mientras tanto, la demanda de té seguía cayendo y la de café se mantenía estable en niveles bajos. En cuanto a las papas, que eran, como hemos dicho, un bien inferior con precios relativos bajos, su consumo per cápita aumentó un 43\% entre 1930 y 1931, volviendo a los niveles de la década de 1910. Sin embargo, ya en 1932 su demanda volvió a caer y repetiría, al final de los años treinta, los índices de los años veinte, evidencia de la recuperación económica. ${ }^{24}$

El consumo de leche no descendió, sino que incluso aumentó con la crisis en un 5\%: en 1940 era un 20\% superior al de 1930 (Birentzwaig, 1982: 610). Para entonces, la Argentina se había convertido, con sus 135,3 litros de consumo de leche per cápita anual, en uno de los dos mayores demandantes de ese producto (junto con el Uruguay) en Sudamérica, cuadruplicando a Brasil (donde era de 37,3 litros) y llegando a ser nueve veces el de Chile. El consumo de manteca (mantequilla), un producto que antes se exportaba a Europa, cambió la ecuación: a partir de 1933 fue más lo que se consumió en el país que lo que se exportó. Su demanda creció con la crisis: pasó de 0,98 kilos per cápita en 1929 a 1,58 en 1933 y a 1,95 en 1939. También aumentó el consumo de queso con la recuperación económica: de 1,55 kilos en 1929 a 1,73 en 1934 y a 3,75 en 1939 (Llorens, 1942: 74-75, 211-212, 218).

El mercado del aceite sufrió cambios en cuanto al tipo de bien demandado pues se introdujo el uso del girasol. Este producto entraba de manera perfecta en el nuevo escenario: tenía una calidad aceptable y era más barato que el de oliva que tanto gustaba a los inmigrantes, pero cuyo precio, dado que era importado, lo hacía poco accesible para los tiempos de crisis. En 1938 el consumo de aceite de maní era de 5.654 litros, el de nabo de 8.548 y el de girasol alcanzaba los 53.277 litros. ${ }^{25} \mathrm{~A}$ partir de entonces, este producto se convertiría, por varias décadas, en el preferido de las familias de ingresos medios y bajos.

La cerveza experimentó una fuerte caída: de los 18 litros en la década previa a la crisis pasó a la mitad, cifra que mantuvo hasta los años cuarenta, sin recuperar su popularidad anterior hasta mucho tiempo después. Este fue el resultado de los esfuerzos de los productores de vino por ocupar un mayor espacio en el segmento de las bebidas alcohólicas. El consumo de vino se desplomó entre 1930 y 1932 de 50 a 35,3 litros por persona, mientras el precio promedio subió de \$ 0,349 a \$ 0,415 el litro. En 1933 el precio bajó a \$ 0,361 y en 1934 a \$ 0,295 y allí se produjo la recuperación. ${ }^{26}$ Así, en el mediano plazo, su consumo cayó menos inicialmente que el de la cerveza -un 40\%- y se recuperó más pronto: en 1937 prácticamente había alcanzado los niveles de 1929. Los problemas en la producción y el consumo de vino fueron encarados por la Sociedad Vitivinícola de Mendoza entre 1929 y 1932, que ayudó a posicionar mejor a la bebida en la demanda nacional (Barrio,

24 El consumo de papas había sido resistido por la población del sur de Italia y solo se había adoptado como sustituto frente al hambre. Ver Arcondo (2002: 276).

25 (Junio de 1940), Revista de Economía Argentina, núm 264, p. 171.

26 (Julio 1945), Revista de Economía Argentina, núm 325, pp. 330-332. 
2018). En la provincia se discutió de manera abierta la necesidad de aumentar el consumo nacional de vino y se propusieron modernas estrategias de capacitación para aumentar la demanda de la clase media (Mateu, 2016). Sin embargo, no fue el vino de calidad el que incrementó las ventas. Uno de los mayores éxitos de los años treinta fue el de la bodega "La Superiora", con instalaciones en San Juan y Mendoza, que ofreció en ese periodo extraordinarios dividendos que iban del 12 al 15\%. ${ }^{27}$ En 1927, la empresa firmó un convenio con el Ferrocarril Buenos Aires al Pacífico para unir sus bodegas de Cuyo con la estación de Palermo, donde construyó instalaciones que convertirían a esa zona de Buenos Aires en el mayor depósito de vinos del país. Las restricciones presupuestarias que impuso la crisis llevaron a su firma a la cima del mercado de vinos: abrió bocas de expendio en Buenos Aires para vender vino suelto a bajo precio, además de sus damajuanas "La Superiora", un artículo barato y de baja calidad que resultó la marca más popular de la época (French Matheu, 1947).

Los artículos considerados de lujo fueron los que más sufrieron la crisis, como ocurrió con las galletitas saladas crackers, que se habían imitado de sus similares provenientes de los Estados Unidos en 1927, y debieron dejar de producirse; y las barras de chocolates Kelytos de la compañía Noel, el mayor éxito de la empresa en los años veinte. Como señalaba esta firma en su Memoria de 1932, "las ventas se resintieron en general, y con más razón en renglones de nuestra industria, considerados como artículos de lujo, aunque muy consumidos en época normales". 28 Por el contrario, un producto de la época fue la fundación de las Grandes Despensas Argentinas, una cadena creada en 1932 por la empresa Bunge y Born que vendía mercaderías a precios baratos. En 1938 ya tenía 148 negocios y había llevado a la bancarrota a pequeños almaceneros que no podían competir con sus precios (Spivacow, 1995: 115).

Entre 1933 y 1943 se produjo un descenso en la participación de la alimentación dentro del presupuesto de los obreros asalariados de Buenos Aires: si en 1933 representaban el 57,5\% del gasto, en 1935 fue del 56,9\% y en 1943 del 46,7\%. Estos números sugieren que estaban dedicando mayores sumas al consumo de otro tipo de bienes, como la indumentaria (Marshall, 1981:354). El desarrollo local de la industria textil y del calzado acompañó los aumentos en la demanda. En 1934, el consumo per cápita de calzados de cuero cayó de los 1,31 pares de 1929 a 1,11, pero comenzó a recuperarse a partir de 1935; en 1939 llegó a los 6,4 pares, mientras en Uruguay era de 1,2; en Brasil de uno y en Chile de 0,7. En 1929, el consumo de tejidos de lana y algodón en Argentina llegaba a los 1.180 gramos por persona, pero durante 1935-1939 alcanzó los 4 kilos de tejidos de algodón y los 0,8 de lana per cápita pasando, en 1940-1945, a los 3,59 y 1,4 kilos (Poblete Troncoso, 1946: 163-168, Mazziotta, 1963: 11).

Las estadísticas elaboradas por el DNT en 1933 mostraban un abanico más grande de bienes que los agregados elaborados con anterioridad, como una mayor

27 Monitor de Sociedades Anónimas, Asambles anuales ordinarias 1931-1940.

28 Noel S. A., Memoria y Balance correspondientes al año 1932. 
variedad en la vestimenta y la aparición de artículos de menaje como las baterías de cocina, la cristalería, los cubiertos, la loza y la ropa de cama. El promedio de esos artículos que poseía una familia obrera resulta revelador: una batería de cocina con tres cacerolas, una docena de copas y una de vasos, 12 cucharas, 12 tenedores y 12 cuchillos, todos de aluminio, algunos pocos platos de loza, seis sábanas con sus fundas y frazadas, dos manteles y 12 servilletas. ${ }^{29} \mathrm{El}$ jabón, por otra parte, ya figuraba para el Departamento Nacional de Trabajo como un artículo de primera necesidad, tanto para lavar la ropa como para bañarse: la campaña de un baño al día de empresas como la británica Lever y las locales Guereño, Llauró y Federal, que estuvieron entre las que obtuvieron más ganancias en la década, parecía haber tenido éxito. ${ }^{30}$

Las estimaciones de Llorens en la Revista de Economía Argentina sobre la capacidad económica per cápita de las provincias (una aproximación al producto bruto geográfico) en 1937 muestran fuertes diferencias entre las zonas más ricas y las más pobres de la Argentina. La ciudad y la provincia de Buenos Aires ocupaban el lugar preferencial. Santa Fe y Córdoba estaban entre un 25\% y un 32\% abajo. Jujuy, Tucumán y Salta, representaban alrededor de un 40\% en relación a la región más próspera, mientras La Rioja, Catamarca y Santiago alcanzaban solo un 10\% (Llorens, 1942: 64). Es probable que los números de Llorens sean demasiado bajos para el norte. Estimaciones recientes muestran que en 1946 las provincias más pobres de esa zona habrían tenido un producto bruto geográfico per cápita que representaba un 40\% del que tenían las regiones más ricas del país (Talassino, 2015).

El panorama sanitario mejoró algo al disminuir la presencia del paludismo. Las políticas de Carlos Alberto Alvarado -Director Regional del Paludismo desde 1933- y Miguel Sussini con la burocratización del manejo de la enfermedad y los planes de Alberto Barbieri redujeron la incidencia de la misma por medio de un limitado saneamiento, combinado con el uso de la quinina, aunque la erradicación del paludismo recién llegaría con el peronismo y sus grandes campañas. En la década de 1920 había comenzado seriamente la lucha contra el mal de Chagas, con la presencia de Salvador Mazza en las zonas más afectadas. Los resultados de las políticas fueron alentadores, pero limitados (Lorenzano, 2003). Sin embargo, las condiciones de nutrición y salud deben haber mejorado si analizamos las estaturas de los conscriptos del norte nacidos en la década de 1930. Si bien las de los santiagueños, que eran los más altos, casi no aumentaron, sí se produjo un crecimiento entre los que eran tradicionalmente más bajos en la región: los jujeños (que antes alcanzaban la menor estatura) crecieron un centímetro, los salteños un centímetro y medio y los tucumanos y catamarqueños algo menos de un centímetro (Salvatore, 2004b: 308).

29 DNT, Boletín Informativo del Departamento Nacional del Trabajo, Año XVI, núm. 169, Época VI, febrero de 1934, pp. 3818-3820.

30 DNT, División de Estadística, Investigaciones Sociales, Buenos Aires, 1936, p. 20. 
La crisis de 1930 reveló que las diferencias regionales continuaban. La caída en la demanda de pan como consecuencia de la debacle, que había sido pequeña en las zonas más ricas del país, se había dado con mayor fuerza en las zonas más pobres; en Santiago del Estero las panaderías señalaban en 1933 que vendían la mitad que tres o cuatro años atrás. ${ }^{31}$ Pero sobre todo, la pobreza de ciertas partes de la Argentina se volvió más visible. Las zonas más ricas del país veían que "el granero del mundo" sufría problemas de subconsumo en los espacios más pobres de la misma nación. Este interés acompañó las notas que aparecieron en la prensa de Buenos Aires en 1937, con la firma de personajes tan populares como Homero Manzi y Roberto Arlt, que revelaban las penurias del interior; describían la sequía de la provincia de Santiago del Estero, resultado de la tala ilimitada de los bosques de quebracho, con imágenes fotográficas de personas hambrientas y desnutridas (Andermann, 2012). El informe del director general de Estadística, Registro Civil y Trabajo de Santiago del Estero, Amalio Olmos Castro, mostraba dos realidades terribles de la provincia en 1937. Por un lado, los 45.000 trabajadores de los obrajes que vivían condenados a la reducción de su salario a la mitad por comprar obligatoriamente en las proveedurías de las empresas. Por el otro, los 50.000 santiagueños que iban todos los años a trabajar como mano de obra temporaria a otras regiones, produciendo un éxodo que -para el funcionario- recordaba escenas bíblicas e impresionaba por el aspecto miserable de las caravanas que se dirigían a las pampas o a la zafra azucarera de Tucumán. ${ }^{32}$

\section{Conclusiones}

Los contrastes en cuanto a pautas de consumo entre el período "dorado" de 19031913, las décadas de 1920 y la de 1930 son fuertes en varios sentidos. Los años de la Belle Époque mostraron una desigualdad social que llevó a que el consumo aumentara más por cantidad que por calidad: la promotora del aumento en la demanda fue la masiva llegada de inmigrantes y no la mejora en el salario real. La década de 1920 y las administraciones radicales dieron vuelta el tema de la cuestión social y crearon un Estado de Bienestar incipiente que, pequeño frente al peronismo posterior, resultó un avance significativo respecto del periodo previo a la llegada de Yrigoyen al gobierno. El partido radical elegía ya con claridad sus votantes, como se mostraba en su propaganda electoral: la clase obrera y su hermana la clase media. Esta construcción fue ayudada por un contexto excepcionalmente bueno en el comercio exterior -lo que le permitía sostener fiscalmente sus gastos- y por la resignación al reformismo del empresariado temeroso de la avalancha roja, unido a las estrategias pragmáticas del sindicalismo gremial. Esta conjunción de factores llevó a la Argentina una explosión en el consumo. Las cantidades aumentaron, salvo que la demanda estuviera satisfecha, y las calidades mejoraron, con un aumento en la presencia de los bienes superiores y la caída de los inferiores. 
La crisis que estalló en 1929 tuvo efectos diferenciados sobre el consumo argentino, aun cuando la demanda se recuperó junto con la economía a partir de 1933. Por un lado, el consumo de los sectores populares se alejó del promedio por la caída inicial y el posterior estancamiento en los salarios reales en la mayoría de los obreros, lo que llevó a que el factor trabajo, que había sido caro por su escasez y por ello atraído a numerosos inmigrantes, se volviera más barato. La caída se produjo no en la cantidad sino en la calidad de los productos consumidos. Los bienes de consumo popular que más éxito tuvieron en la década de 1930 fueron aquellos de calidad más baja y, por ende, de más bajo precio. Por otro lado, las divergencias regionales se volvieron quizá más visiblemente graves que antes -en todo caso, no mejoraron mucho- en parte porque los habitantes de las zonas más prósperas encontraron una sensibilidad especial para afrontar los problemas de una Argentina profundamente dividida y pudieron constatar que el desequilibrio tradicional se trasladaba sin interrupción a los alrededores de sus propias ciudades por las migraciones internas. Y se produjo un fenómeno que el consumo muestra como difícil de revertir. El avance social en las regiones más prósperas a través de la distribución del ingreso que el radicalismo y el peronismo habían logrado se volvió más limitado en las diferencias regionales (que el desarrollismo intentará terminar). Estas divergencias, que apenas se podían encontrar en países como Australia, y que no eran tan agudas en aquellos que sí las tenían pero que las lograron revertir, como ocurría en el sur en los Estados Unidos y en Quebec, en el Canadá, continuaron en los comportamientos referidos al consumo.

Este es el panorama que encontró Juan Domingo Perón desde que asumió como Secretario de Trabajo y Previsión en 1943 y que enfrentó en las discusiones como miembro del Consejo Nacional de Posguerra. Si en algún momento pudo haber favorecido la idea de un país exportador de industrias con salarios reales bajos, muy pronto se inclinó por un esquema que pivotaba en torno a la producción para el mercado interno con salarios reales altos. El boom de consumo de los primeros años de la presidencia de Perón (1946-1949) fue el más significativo del siglo XX. La ampliación de la clase media durante el peronismo siguió la tendencia de los años veinte que la crisis había detenido. Este proceso continuó después de la caída de Perón y durante la expansión económica que inició el desarrollismo,y se mostró también en las altas tasas de crecimiento económico del periodo 1963-1973. Ello terminaría con la crisis de 1975 y la dictadura militar de 1976, cuando el atraso económico relativo de la Argentina se convirtió en caída libre y retraso absoluto, una trayectoria entre cuyas variables más significativas, por la magnitud de su descenso, estuvo el consumo. 


\section{Bibliografía}

" Alvaredo, F. (2007). The Rich in Argentina over the Twentieth Century, 1932-2004. Atkinson, A. B. y T. Piketty (eds.), Top incomes: A global perspective. Oxford: Oxford University Press, pp. 253-298.

"Andermann, J. (2012). El infierno santiagueño: sequía, paisaje y escritura en el Noroeste argentino, Iberoamericana, 12 (45), pp. 23-43.

"Aráoz, M. F. y E. Nicolini (2015). Persistence vs. Reversal and Agglomeration Economies vs. Natural Resources. Regional inequality in Argentina in the first half of the Twentieth Century, Universidad Carlos III, Working Paper 15-05, pp. 1-22.

" Arcondo, A. (2002), Historia de la alimentación en Argentina. Desde los orígenes hasta 1920. Córdoba: Ferreyra Editor.

" Barrio, P. (2018). La Sociedad Vitivinícola de Mendoza, 1929-1932. Bosquejo histórico, Ponencia presentada en las XXVI Jornadas de Historia Económica, 21 al 23 de septiembre, Asociación de Historia Económica/Universidad Nacional de La Pampa.

" Bennett, M. K. (1951). International Disparities in Consumption Levels. The American Economic Review, 41 (4), pp. 632-649.

" Birentzwaig, A. E. (dir.). (1982). Relevamiento estadístico de la República Argentina 19001980. Buenos Aires: Banco de análisis y computación.

" Bragoni, B. y P. Olguín (2016). Salarios, precios y nivel de vida en Mendoza durante la gran transformación vitivinícola (1890-1914), Folia Histórica del Nordeste, núm 26, pp. 156-177.

" Briones, C. (2016). Constructing Public Statistics: The History of the Argentine Cost of Living Index, 1918-1943. Ph.D Dissertation, Londres, London School of Economics and Political Science.

" Bunge, A. (1920). Los problemas económicos del presente. Buenos Aires: s.e.

"Bunge, A. (1928). La economía argentina. Buenos Aires: Agencia General de Librería y Publicaciones.

"Caldo, P. (2009). Mujeres cocineras. Hacia una historia sociocultural de la cocina, Argentina a fines del siglo XIX y primera mitad del XX. Rosario: Prohistoria.

"Campi, D. (2004). La evolución del salario real del peón azucarero en Tucumán (Argentina) en un contexto de coacción y salario arcaico (1881-1893), América Latina en la Historia Económica, núm 22, pp. 105-128.

" Carter E. D. (2012). Enemy in the Blood. Malaria, Environment and Development in Argentina. Tuscaloosa: The University of Alabama Press.

"Celton, D. E. (1992). La mortalidad en la ciudad de Córdoba (Argentina) entre 1869 y 1990. Boletín de la Asociación de Demografía Histórica, X (1), pp. 31-57.

"Centro Azucarero Nacional (1935). La Industria Azucarera. Buenos Aires: Talleres Ferrari Hnos.

" Coria, L.A. (2004). El producto bruto geográfico de Mendoza para 1914, Metodología y resultados. Mendoza: Facultad de Ciencias Económicas, Universidad Nacional de Cuyo.

"Correa Deza, M. F. (2007). Evolución del salario real del peón azucarero de Tucumán, 1904-1927, Tesina de licenciatura inédita, Facultad de Ciencias Económicas, Universidad 
Nacional de Tucumán.

"Correa Deza, M. F. (2008). Aproximación a una serie de precios para Tucumán, 1904-1927. Ponencia presentada en las XXI Jornadas de Historia Económica, 23 al 26 de septiembre, Asociación Argentina de Historia Económica/Universidad Nacional de La Plata.

"Cortés Conde, R. (1978). El progreso argentino 1880-1914. Buenos Aires: Sudamericana.

" Cuesta, E. M. (2012). Precios y salarios en Buenos Aires durante la gran expansión (18501914). Revista de Instituciones, Ideas y Mercados, núm 56, pp. 159-179.

"Cuesta, E. M. (2014). Precios, salarios y empresa en la Argentina próspera. El caso del Mercado Central de Frutos (1887-1930). H-Industri@ Revista de Historia de la industria, los servicios y las empresas en América Latina, 14 (8), pp. 121-152.

" Deaton, A. (2015). El gran escape. Salud, riqueza y los orígenes de la desigualdad. México: FCE.

"Djenderedjian, J. (en prensa). El nivel de vida en un país naciente y diverso. Salarios, precios de alimentos y cobertura de una canasta de subsistencia en las 14 provincias de Argentina, 1875. Investigaciones de Historia Económica-EconomicHistoryResearch.

"Fernández, A. (2004). Un mercado étnico en el Plata. Emigración y exportaciones españolas a la Argentina (1880-1935). Madrid: Consejo Superior de Investigaciones Científicas.

"Ferreras, N. O. (1998). La cuestión de la alimentación obrera en Buenos Aires y Rio de Janeiro entre 1930 y 1945. Estudios IberoAmericanos, XXXIV (2), pp. 93-111.

" Ferrreres, O (2010). Dos siglos de economía argentina (1810-2020). Buenos Aires: Fundación Norte y Sur.

"French Matheu, V. (1947). Don Manuel L. Lemos y su obra argentinista. Buenos Aires: Talleres Gráficos G. Kraft.

" Gelman, J. (2011). El mapa de la desigualdad en la Argentina del siglo XIX. Rosario: Prohistoria.

" Gerchunoff, P. y H. Aguirre (2006). La economía argentina entre la gran guerra y la depresión. Oficina de la CEPAL Buenos Aires, Serie Estudios y Perspectivas, núm 32, pp. 1-87.

" Gerchunoff, P., F. Rocchi y G. Rossi (2008). Desorden y progreso: las crisis económicas argentinas, 1870-1905. Buenos Aires: Edhasa.

" Gerchunoff, P. (2016). El eslabón perdido: la economía política de los gobiernos radicales (1916-1930). Buenos Aires: Edhasa.

" González Bollo, H. (2013). Francisco Latzina (1843-1922), funcionario estadístico del Estado argentino (1880-1916). Estatística e Sociedade, pp. 110 - 121

" Gutiérrez. L. (1981). Condiciones de vida material de los sectores populares en Buenos Aires, 1880-1914. Revista de Indias, núm 163-4, pp. 167-202.

" Hora, R. (2015). Repercusiones de la gran depresión en la sociedad argentina. Drinot, P. y A. Knight (coord.), La gran depresión en América Latina. México: Fondo de Cultura Económica.

"Horowitz, J. (2015). El radicalismo y el movimiento popular. Buenos Aires: Edhasa.

" Iñigo Carrera, J. (2007). La formación económica de la sociedad argentina. Volumen I. Renta agraria, ganancia industrial y deuda externa. 1882-2004. Buenos Aires: Imago Mundi.

" Ledesma, L. (2015). Mercadería fresca y al alcance de todos los hogares... Consumos 
básicos y consumidores en el Territorio Nacional de La Pampa, ca. 1895-1945, en A. Lluch, Las manos visibles del mercado. Rosario: Prohistoria, pp. 191-214.

" Ledesma, L. (2017). Condiciones y niveles de vida en el interior de Argentina. Territorio Nacional de La Pampa, primera mitad del siglo XX. En Lluch, A. (ed). Desarrollo, políticas públicas e instituciones: la experiencia de la pampa en una visión de largo plazo. Santa Rosa: EdUNLPam, pp.194-220.

" Lobato, M. Z. (2017). Historia de las instituciones laborales en Argentina: una asignatura pendiente. Revista del Trabajo, núm 4, pp. 145-154.

"Lorenzano, C. (ed.). (2003). Historias de la Ciencia Argentina I. Caseros: EDUNTREF.

" Llach, J. J. (1984). El Plan Pinedo de 1940, su significado histórico y los orígenes de la economía política del peronismo. Desarrollo económico, 23 (92), pp. 515-558.

" Llach, L. (2007). The Wealth of the Provinces: The Rise and Fall of the Interior in the Political Economy of Argentina, 1880-1910, Ph.D Thesis, Boston, Harvard University.

" Llorens, E. (1942). El subconsumo de alimentos en América del Sur. Buenos Aires: Sudamericana.

" Lluch, A. (2013). Marca registrada... Reflexiones sobre el uso de las marcas comerciales, el consumo y la comercialización de bienes en el mundo rural argentino (1900-1930). Mundo Agrario, 13 (26), pp. 1-29.

" Lluch, A. (ed.) (2015). Las manos visibles del mercado: Intermediarios y consumidores en la Argentina (Siglos XIX y XX). Rosario: Prohistoria.

" Malaurie, A. y Gazzano, J. (1888). La industria argentina y la exposición del Paraná. Buenos Aires: Agencia General de Publicidad de Juan M. Gazzano y Cía.

" Marshall, A. (1981). La composición del consumo de los obreros industriales de Buenos Aires, 1930-1980, Desarrollo Económico, 21 (83), pp. 351-374.

" Martirén, J. L. y Rayes, A. (2016). La industria argentina de trigo en el cambio de siglo. Límites y alcances 1880-1914, H-Industri@ Revista de Historia de la industria, los servicios y las empresas en América Latina, 18 (10), pp. 1-27.

" Martirén, J. L. y Moyano, D. (2016). Diferenciar lo semejante. Publicidad y construcción de marcas de bienes de consumo en la industria azucarera y harinera (Tucumán y Santa Fe, fines del siglo XIX). Ponencia presentada a la VII Reunión del Comité Académico de Historia, Regiones y Fronteras, San Miguel de Tucumán, 14 y 15 de abril.

" Martirén, J. L. y Moyano, D. (2019). La formación de mercados de alimentos en Argentina: un análisis sobre la comercialización de las harinas de trigo entre Santa Fe y las plazas norteñas (1880-1895). América Latina en la Historia Económica, 26 (1), pp. 47-71.

" Mateu, A. M. (2016). La vitivinicultura mendocina de entreguerras. Herencia e innovación en las crisis productivas (1914-1940), RIVAR, 3 (9), pp. 75-103.

" Mazziotta, M. (1963). El crédito bancario como factor de desarrollo y expansión de la industria textil y complementarias. Tesis de doctorado, Facultad de Ciencias Económicas, Universidad de Buenos Aires.

" Milanesio, N. (2006). The Guardian Angels of the Domestic Economy: Housewives' Responsible Consumption in Peronist Argentina. Journal of Women's History, 18 (3), pp. 91-117.

" Milanesio, N. (2014). Cuando los trabajadores salieron de compras. Nuevos consumidores, publicidad y cambio cultural durante el primer peronismo. Buenos Aires: Siglo Veintiuno.

" Moreyra, B. (2000, 2001). Estado, mercado y sociedad. Córdoba 1820-1950. Tomos I y II. 
Córdoba: Centro de Estudios Históricos "Prof. Carlos S. A. Segreti" y Agencia Nacional de Promoción Científica y Tecnológica.

"Moyano, D. (2012). Las formas del dulce. Producción, mercados y tipos de azúcares en la agroindustria tucumana (1870-1914). Revista de Historia Americana y Argentina, Universidad Nacional de Cuyo, 47 (2), pp. 113-173.

" Moyano, D. (2017). El lánguido final de una empresa emblemática. Refinería Argentina y la readecuación del holding Tornquist ante los cambios del mercado azucarero (19051935). Ponencia presentada en el XI Congreso Internacional de Economía y Gestión, Buenos Aires, 3 al 5 de octubre.

"Otero, H. (2007). Estadística y nación. Una historia conceptual del pensamiento censal de la Argentina moderna (1869-1914): Buenos Aires: Prometeo.

" Pastoriza, E. (ed.) (2002). Las puertas al Mar. Consumo, ocio y política en Mar del Plata, Montevideo y Viña del Mar. Buenos Aires: Biblos.

"Pérez, I. (2012). El hogar tecnificado: familias, género y vida cotidiana. Buenos Aires: Biblos.

"Pérez, I. (2015). Apuntes para el estudio del consumo en clave histórica. Avances del Cesor, XII (13), pp. 97-106.

"Pérez, I. (2017). Género y consumo: una revisión de la producción historiográfica reciente sobre América Latina en el siglo XX. Historia Crítica, 65, pp. 29-48.

" Pineda,Y. (2018). Farm Machinery Users, Designers, and Government Policy in Argentina, 1861-1930. Agricultural History, 92 (3), pp. 351-379.

" Poblete Troncoso, M. (1946). El subconsumo en América del Sur. Alimentos, vestuario y vivienda. Santiago de Chile: Editorial Nascimento.

" Remedi, F. (2004). El consumo alimentario en la provincia de Córdoba 1870-1930. Tesis de doctorado, Universidad Nacional de Córdoba.

" Remedi, F. (2017). Modernidad alimentaria y afrancesamiento. Ciudad de Córdoba (Argentina) en el tránsito del siglo XIX al XX. Historia Crítica, 65, pp. 71-92.

" Richard-Jorba, R. (2010). Empresarios ricos, trabajadores pobres. Vitivinicultura y desarrollo capitalista en Mendoza (1850-1918). Rosario: Prohistoria.

" Rocchi, F. (2006). Chimneys in the Desert: Industrialization in Argentina during the export boom years, 1870-1930. Stanford: Stanford University Press.

" Rocchi, F (2016a). Consumption in Latin America. Oxford Handbooks Online, Oxford University Press, Scholarly Research Reviews.

" Rocchi, F. (2016b). A la vanguardia de la modernización: la incipiente formación de un campo publicitario en la Argentina durante la década de 1920, Estudios Interdisciplinarios de América Latina y el Caribe, 26 (2), pp. 45-76.

" Rocchi, F. (2017). La sociedad de consumo en tiempos difíciles: el modelo estadounidense y la modernización de la publicidad argentina frente a la crisis de 1930". Historia Crítica 65, pp. 63-114.

"Salas Arón, E. (2019a). Un camino virtuoso hacia la desigualdad: riqueza y distribución del ingreso en la Argentina de la primera globalización, 1913. Ponencia presentada en el Sexto Congreso Latinoamericano de Historia Económica, 23 al 25 de julio, CLADHE/ Universidad de Santiago de Chile.

"Salas Arón, E. (2019b). De la federación al leviatán: una mirada sobre las fiscalidades del estado central y las provincias en la Argentina de la primera globalización (1880-1918). XXII Seminario de Federalismo Fiscal, Universidad Torcuato Di Tella. 
"Salvatore, R. (2004a). Stature decline and recovery in a food rich export economy: Argentina 1900-1934". Explorations in Economic History, 41 (3), pp. 233-255.

"Salvatore, R. (2004b). Stature, Nutrition, and Regional Convergence. The Argentine Northwest in the First Half of the Twentieth Century. Social Science History, pp. 297-324.

"Salvatore, R. (2005). Yankee Advertising in Buenos Aires: Reflections on Americanization. Interventions: International Journal of Postcolonial Studies, 7 (2), pp. 216-235.

"Salvatore, R. (2010). Better-off in the thirties: Welfare Indices for Argentina, 1900-1940, en Salvatore, R., J. Coatsworth y A. Challú (eds.). Living Standards in Latin American History: Height, Welfare and Development, 1750-2000. Cambridge: Harvard University Press, 2010, pp. 127-166.

"Sánchez Katz, G. (2016). Crecimiento, modernización y desigualdad regional. La Belle Époque argentina. Revista Estudios Avanzados, núm 25, pp. 42-67.

"Sánchez Wilde, A. (1993). La formación del mercado laboral de la industria azucarera en Tucumán y sus consecuencias sociales. Una aproximación a la evolución del salario real del peón azucarero. (1880-1896), Tesina de licenciatura, Facultad de Ciencias Económicas, Universidad Nacional de Tucumán, 1993.

"Santilli, D. (2019). Dos siglos de desigualdad. ¿Qué sabemos? Un parcial estado del arte en el siglo XIX desde la historia. Quinto Sol, 23 (2), pp. 1-27.

"Sierra e Iglesias, J. (2005). La epidemia de cólera sufrida por la Argentina durante los años 1886 y 1887 y sus incidencias en las provincias de Salta y Jujuy", Tesis de doctorado en Medicina, Buenos Aires, Universidad del Salvador.

"Somoza, J. (1973). La mortalidad en la Argentina entre 1860 y 1960. Desarrollo económico, 12 (48), pp. 807-826.

"Spivacow, B. (1995). Memoria de un sueño argentino. Buenos Aires: Colihue.

"Talassino, M.(2015). Producto Bruto Geográfico de 1946 de las provincias argentinas: Una estimación preliminar. Anales de la Asociación Argentina de Economía Política, L Reunión Anual.

"Tossounian, C. (2016). Milonguitas: Tango, Gender and Consumption in Buenos Aires (1920-1940). Estudios Interdisciplinarios de América Latina y el Caribe, 27 (2), pp. 29-45.

"Trentmann, F. (2017). Empire of Things: How We Became a World of Consumers, from the Fifteenth Century to the Twenty-First. New York: Harper Perennial. 